\title{
The 'Educational Lot' for Young People Who Are NEET: Quality Management and Roles of Management Information Systems
}

\author{
Don Passey \\ Department of Educational Research, Lancaster University, UK \\ d.passey@lancaster.ac.uk
}

\begin{abstract}
The United Kingdom (UK) government, in common with those in many other countries, recognises the significant numbers of young people who are not in education, employment or training (NEET) from the age of 16 years. Perceptions associated with this group of young people have often been negative, yet recent research suggests that reasons for the lack of involvement of this group of young people often arises from situations where there is extreme trauma, linking to desires of individuals to seek alternative forms of educational and economic involvement from the traditionally cognitively focused opportunities accessible normally in schools. Alternatives, sometimes involving uses of technology, are being offered in a range of school and support situations. The importance of management information systems in both identifying and positively tracking these young people is recognised, yet the development of systems to cope with policy and support needs is currently at an early stage. This paper offers an overview of the current, largely UK, context, and indicates how data management information systems are likely to support important policy, practice and research needs.
\end{abstract}

Keywords: Learning management systems, learner-centred learning, motivation, evaluation, policy.

\section{Introduction}

It is well recognised that many young people in the United Kingdom (UK) are not in education, employment or training (NEET) from the age of 16 years. The British Broadcasting Corporation (BBC) reported (Eason, 2007) that: "At the end of 2006 there were said to be 206,000 Neets aged 16 to 18 in England in the target group for the government's new strategy". Raffe (2003) found, in a study conducted in Scotland, that: "more than three in ten $(31 \%)$ young people were NEET at some time during the three years after the end of compulsory schooling". However, the exact numbers of young people who are NEET, particularly at any one point in time, are not at all clear. As the BBC article stated: "Shortcomings in the system that tracks what becomes of young people mean that officials do not know what $5 \%$ are up to - they are simply not on the databases".

A. Tatnall, O.C. Kereteletswe, and A. Visscher (Eds.): ITEM 2010, IFIP AICT 348, pp. 121 129, 2011.

(c) IFIP International Federation for Information Processing 2011 
Many governments wish to address what is seen as a 'NEETs issue'. In 2000, heads of state and governments of the European Union (EU) agreed the 'Lisbon Objectives in Education and Training'; these objectives included the reduction of the high number of early school leavers aged 18 to 24 years to $10 \%$ by 2010 , in order to reduce the danger of them 'being on the fringes of the knowledge society' (Commission of the European Communities, 2005). The second report on progress towards the meeting of those objectives indicated that in 2004 the EU average ratio of early school leavers (referred to as 'drop outs' in EU documentation and NEETs in UK documentation), for those with only 'lower-secondary education' was the same as that in 2003, and that the 2010 target would not be met if this trend were to continue. Within that report, the UK rate was reported as $16.7 \%$ for 2004 (16.4\% for females, and $17.0 \%$ for males). In a UK context, concerns about this group, and perceptions associated with them, are themselves quite diverse. The approaches that can be taken by policy makers and those who support this group can be wide, and these approaches appear to be associated with perceptions of who constitutes this group. At times, perceptions of this group of young people have been painted in rather negative ways. But, as the BBC report stated: "We imagine them to be the idle feckless - good-fornothing layabouts, content to subsist on benefits and/or family handouts. But the government's own strategy document makes it clear this is a misleading impression".

It is clear that many different individuals (and sub-groups) make up this wider NEET group. It is commonly believed that certain factors impact often at early stages, and the potential levels of impact of some factors is alarming; consider, for example, that "Some 78 million Europeans live at risk of poverty, 19 million of whom are children" (European Communities, 2008), or that "6 million young people leave school without any qualifications" (Commission of the European Communities, 2009). There have been a number of different attempts to categorise and characterise this group more exactly, in order that policy makers and support practitioners can be in a position to understand them in greater detail, and support them (or address issues associated with them) more effectively. The BBC report stated that: "Researchers working for the then Department for Education and Skills came up with various characteristics of youngsters who were likely to drop out: Angry young rebels; Quitters; Rebels without a cause; cool dudes; Hedgers; Settlers; Escapists; and Strugglers". A recent study that looked at uses of technology by this group of young people (Passey, Williams and Rogers, 2008) categorised them in ways that were concerned with a focus on potential future support. They suggested using four different categories: those young people who are employment and education ready (EERs); those who are nearly employment and training ready (NEERs); those who have chosen alternative lifestyles (ALTs); and those who have multiple long-term problems (MULPs).

Understanding the characteristics of this group of young people, to consider how to associate most appropriately the alternative forms of support available, is clearly likely to be of importance. The range of characteristics of this group is wide, and some of the features of this group bring particular challenges to any implementation approach. A phenomenon of note is that of NEET 'churn'. A report by the National Audit Office (2004) found that while the majority of young people do leave NEET status, this is not necessarily a permanent exit. They found that a substantial minority continued to join and rejoin the NEET group, with numerous short periods of 
education or employment in between. The NEET group is not a stable group - young people are continually leaving and joining it. Sachdev, Harries and Roberts (2006) reported, for example, that only $1 \%$ of the group remain NEET right through from 16 to 18 years of age.

To positively support these young people, it is clear that there are potential roles for management information systems: to help identify the population more exactly; to identify characteristics that can suggest appropriate engagement; to track and record success as well as indications of weakness; and to provide research with opportunities to address key questions relating to this area. These key areas will be explored further within this paper. It should be noted in this context, however, that inappropriate or inadvertent uses of management information systems could create significant future issues. 'Escapists', for example, are a group of young people likely to be seeking ways to be (rightly) individual, related with high degrees of freedom. Data management systems used to track individuals so that those individuals feel that their freedom is being taken away from them are likely to feel negatively, they may well disengage further, rather than being encouraged to engage positively.

\section{Understanding the Scope of the Problem}

There is a clear need to understand the scope of the problem, if it is to be addressed. Currently, the lack of detailed quantitative information is in itself a weakness. Within the UK, data management systems within schools retain detailed information on individuals. While individuals are within school systems, the recording and retaining of data is widespread and usually thorough. However, when individuals move outside a school system (to another school or beyond), the transfer of data has been less well developed technologically and operationally.

When young people leave the school system, local authority (LA) Connexions services are key agents in providing support for young people who are NEET. Connexions services generally would find it useful to have access to certain types of data that are not currently necessarily easily accessible to them. For example, having end of Key Stage 2 (at 11 years of age) and end of Key Stage 3 (at 14 years of age) subject attainment data would be helpful to them. Some services in some LAs and regions have started to look at how to address this type of need. There is a need, however, for appropriate transfer of data not just from schools to the Connexions services, but also from other LA services to the Connexions service. Currently, this form of transfer is not developed in any common form, but the importance of information and management systems in this respect is stressed by the government education department (DCSF, 2008a) through its website. The website states that: "Connexions has developed excellent case management systems for effectively tracking young people's progress. These systems formed the basis of the Client Caseload Information System (CCIS) specification which enables support to young people across local authority boundaries, ensures multi-agency working and gives better targeting of services; all of which form the heart of any integrated youth support service. Local authorities will be expected to ensure that the client tracking systems set up by Connexions services are maintained and developed to inform local planning and measurement of the NEET group. ... Local authorities must have in 
place a robust client management system and client tracking arrangements that meet the Client Caseload Information System (CCIS) specification." Some local exemplars do currently exist where implementation has been undertaken in particular ways. A report by Citizens Online and the National Centre for Social Research (2008) identified a number of key exemplars of technologies in LAs supporting young people who are NEET, including the YorOK Database (information sharing in multi-agency working). The DCSF (n.d.) website provides a range of case studies, including an example where data is transferred between schools and the Connexions service, called Pan London CCIS. In the state of Victoria in Australia, a Schools Interoperability Framework (SIF) is being used to support data transfer with a focal purpose of enabling the identification and tracking of young people who are NEET (Shoesmith, 2009). Although schools in the state record relevant data, details about young people are not held in the same software applications as data relating to attendance and to timetable. The SIF framework works by using a central Zone Integration Server, which reads data from different sources, and writes them to agreed applications. Each application across the system that contains data of value is read through the use of a SIF agent (a specific piece of software to read that agreed data). In this way, data already across the system can be read and written to other parts of the system, so that a more complete picture becomes accessible to users. This system is in use in certain local authorities and states in the UK, the United States, and Australia. Within the UK, SIF has now been agreed as the form of data transfer that will be central to national policy (see Becta, 2008). It is clear overall that, until this form of data transfer is more commonly accessible, the scope of the problem is not likely to be known exactly. However, even when this is the case, the forms of data retained, to fulfil specific purposes, will need to be considered carefully.

\section{Tracking and Recording Success as well as Weakness}

Perceptions of 'the NEET issue' could well frame the forms of data that are retained in management systems. It is clear from those working within the Connexions and support services currently that tracking and recording success is as important a need as identifying those aspects of weakness that need to be addressed.

In the UK, the DCSF has set up a national dedicated website to support young people who are NEET, called Connexions Direct (CXD). As the DCSF (2008b) says, it: "offers advice, support and information for young people aged 13 to 19 on a wide range of issues relevant to their age group. CXD consists of a dedicated website - for online searching on subjects such as careers, learning, health, relationships, finance and leisure activities and a helpline where young people can access information, advice and support via the telephone, text messaging, webchat and email. The helpline operates from 8.00 am until 2.00 am, 365 days a year, offering useful outof-hours support to complement local provision". However, although this website clearly encourages contact with young people, the ways in which those contacts relate to records created, or how they are integrated with wider uses of a virtual learning environment to support e-portfolio provision, is not indicated there, although a recent report (DCSF, 2009a) states commitment to developing innovative online services, including a growing provision for young people to let others know of 
their experiences, as well as a commitment to developing wider ranges of facilities to link existing online provision. Currently, and in the future, it is arguable that these forms of issue will need to be met and to be considered at a much more local level, with LAs and Connexions services considering the ways in which specific local technological facilities can be integrated. Some Connexions services have already looked at ways to support their needs, and the needs of young people in these respects. A report by Citizens Online and the National Centre for Social Research report (2008) identified an exemplar of use of a form of e-portfolio, called the Virtual Ruksak (allowing young people to record and retain examples of work done in a variety of situations, collected together so that employers and admissions tutors can easily view their achievements). Although these forms of technologies are likely to support these young people, they are not widely available currently. The transfer of records between such systems is also not widespread.

\section{Identifying the Population More Exactly}

Connexions services use particular categories to maintain records of young people, which have been provided from the UK government department, for policy reporting purposes. Experience has shown that placing young people within these categories is not always easy or consistent. The category of 'unemployed' can be very wide, and this group is registered as unemployed with Connexions. Some will also be registered unemployed with Job Centre Plus (when they are post 18 years of age). Other young people may be grouped in categories of 'illness' (which in one Connexions service is used for short term illness), 'unavailable on religious grounds', 'not economically active' (which is used for long-term illness over 12 months or for disability), 'unavailable for other reasons' (which is used when it is not clear that any other category is appropriate), 'young carer' (which is concerned with those caring for relatives), 'young parents', 'pregnant', and 'personal development opportunity' (which covers voluntary work that is both paid and unpaid).

These forms of category, while necessary from a government record viewpoint, appear to be of much less value to those supporting the young people. There is currently no consistent recording approach used across Connexions services in the UK, for example, to identify features that will help those who support the young people. Yet important features of these young people are being identified, and could be considered in the formation of appropriate data recording elements. For example, young people who are NEET commonly exhibit limited capabilities to support decision-making (reported by Passey, Williams and Rogers, 2008). In addition to this limited capability (in terms of decision making), other factors such as traumatic backgrounds and poor experiences of learning environments can mean that young people who are NEET often do not sustain employment or educational opportunities when these are offered to them. These decision-making limitations tend to be linked for many young people who are NEET to particular ways of thinking. They do not tend to think in abstract or theoretical ways, and value 'real-world' experiences. Many young people who are NEET think along practical lines or creative lines, rather than theoretical or cognitive lines that are more abstract. Young people who are NEET 
often engage most readily in practical and creative endeavour, and desire involvement in social environments. How these features can be related to recorded details for those who support these young people is a clear need.

\section{Identifying Predictors of the Issues}

Some schools have already begun to take preventative action with regard to 'the NEET issue'. Some schools are now involved in identifying young people who are not benefiting from the 'traditional' curriculum. They are involved in providing alternative curriculum opportunities, with the intention of supporting the needs of young people who might have moved into the NEET group. In one school federation, inclusion advocates in each school identify young people (through their behaviour patterns) who might in the future become NEET.

However, this identification of the group of 'potential young people who will become NEET' is based on particular assumptions. These assumptions are not necessarily universally held. Some managers of Connexions services, for example, feel that those young people who become NEET may actually be in a category in school associated with the quiet, low achievers, rather than those identified as disengaging and identifiable through their external behaviour patterns. There is clearly a role for management information systems in helping to explore and address this question; the data held in systems is likely already to enable a study to look at the match of these features. It is generally accepted that there is a need to identify early the characteristics which put young people at risk of becoming long-term NEET. UK government policy (DCSF, 2009b) now expects this group to be supported by alternative curriculum provision (including a range of new more practically focused diplomas accessible to young people 14 to 19 years of age); it is clear that research is needed in order to demonstrate much more precisely what the outcome of this provision will be for the young people. A long-term study of this form is currently being set up in Scotland (Longitudinal Studies Centre, 2009).

\section{Ethical Issues, Positive Intentions and Engagement}

Although this paper is not specifically focusing on an in-depth discussion of ethical or wider issues concerned with engagement of young people who are NEET, it is worth highlighting a number of points of pertinence within this context. What is clear from background literature is that young people who are NEET may well have had negative experiences in school situations, have found concentrating within classrooms to be difficult, have sought engagement in training and employment that is practically, creatively or socially based, but have been hampered by their limitations with regard to a range of positive experiences and how to handle decision-making. If numbers of these young people are to be engaged positively (helping them to explore opportunities and find unrecognised areas of interest), then evidence of outcomes so far suggests that there is a need to do more; and that that need should include more positive support, using data management and associated research positively within 
this context; the purpose of the use of data, and research using data, needs to positively support young people, rather than encroach on their privacy, or individualism, or to 'keep track of them'. Research in this context has a role in identifying answers that can be of benefit to the young people; this paper does not argue for widespread tracking, or for an encroachment that could lead to a generation of antagonism. In that respect there is a need to consider individuals, as well as to consider protection of data, appropriate use of data, and appropriate elimination of data when answers have been identified. While the rights of individuals need to be upheld, a further dimension to consider is the financial support that agencies and governments provide; it is arguable that those who provide funds have a right to know how those funds are used and what outcomes arise.

\section{Research, Policy and Practice Needs}

Evidence indicates that roles for management information systems in supporting 'the issue of NEETs' are well and widely recognised, but that implementation, practice and features of use are only at early stages. The current situation indicates that there are some key potential roles in the areas of research, policy, and practice.

In terms of policy, key questions with regard to data management systems relate to the ways in which data transfer will be enabled, the details recorded to enable an understanding of scope, the forms of presentation that will be of value to different users of the system, how systems will track and record successes as well as weaknesses, how the details presented will be of direct value to those supporting the young people (or to the young people themselves even more ideally), and how the data systems will provide timely data to support prevention of severe situations arising. In terms of practice, key questions with regard to data management systems relate to the ways in which data will be accessible to the user, the details recorded to enable an understanding of scope within their localities, the forms of presentation that will offer value to that particular user, how systems will provide a view of the young people's successes as well as their weaknesses, and how the data systems will provide alerts of severe situations arising. In terms of research, key questions with regard to data management systems relate to the ways in which data can provide an exploration of scope of the issues, how the data can enable a more thorough understanding of the population and how support will relate to those features that are identified, how systems will provide a view of the young people's successes as well as their weaknesses to enable measures of success that can be made more widely accessible to the profession, and how the data systems can provide opportunities to explore predictors of 'the issues of NEETs', so that young people can gain from positive, supportive intervention. Data management systems have the potential to offer substantial future value to those concerned with 'NEETs issues' in policy, practice and research areas. Although there is likely to be a range of technological issues that will need to be addressed if they are to fulfil their widest potential, even exploring uses of current data management systems to look at some of the many assumptions that exist are likely to be fruitful at this stage. 


\section{Acknowledgements}

The author would like to thank Becta for their funding of key elements of the background research reported in this paper. This paper does not, however, represent any official statement or view of Becta.

\section{References}

Becta: Statement of intent on interoperability from DCSF, DIUS and Becta. Becta, Coventry (2008), http://news.becta.org.uk/display.cfm?resID=37481 (accessed August 14, 2008)

Citizens Online and National Centre for Social Research: Digital Exclusion Profiling of Vulnerable Groups. Young People not in Education, Employment or Training (NEET): A Profile. DCLG, London (2008)

Commission of the European Communities: Commission Staff Working Paper: Progress towards the Lisbon Objectives in Education and Training. Commission of the European Communities, Brussels (2005)

Commission of the European Communities: Communication from the Commission to the Council, the European Parliament, the European Economic and Social Committee and the Committee of the Regions: An EU Strategy for Youth - Investing and Empowering: A renewed open method of coordination to address youth challenges and opportunities. Commission of the European Communities, Brussels (2009)

Department for Children, Schools and Families: Every Child Matters: Change for Children. Information Systems. DCSF, London (2008a),

http: / / www. everychildmatters.gov.uk/youthmatters / connexions / i nformationsystems / (accessed January 7, 2009)

Department for Children, Schools and Families: Every Child Matters: Change for Children. Connexions Direct (CXD). DCSF, London (2008b),

http: / /www. everychildmatters.gov.uk/youthmatters/connexions / cxd/ (accessed January 7, 2009)

Department for Children, Schools and Families: Quality, Choice and Aspiration: A strategy for young people's information, advice and guidance. DCSF, London (2009a)

Department for Children, Schools and Families: 14-19 Reform: The Diploma entitlement. DCSF, London (2009),

http://www.dcsf.gov.uk/14-19/index.cfm?go=site.home\&sid= $42 \& \mathrm{pid}=534 \& \mathrm{ctype}=$ None\&ptype=Contents $($ accessed December 9, 2009)

Department for Children, Schools and Families: 14-19 education and skills: NEET Guidance and Case Studies. DCSF, London (n.d.),

http://www.dcsf.gov.uk/14-19/index.cfm?go=site.home\&sid= $42 \& \mathrm{pid}=343 \& \mathrm{id}=540 \& \mathrm{ctype}=$ None\&ptype=Content $\mathrm{s}($ accessed January 7, 2009)

Eason, G.: NEETs are an unknown quantity. BBC News, London (2007), http://newsvote.bbc.co.uk/mpapps/pagetools/print/ news.bbc.co.uk/1/hi/education/7079780.stm (accessed January 13, 2009)

European Commission: What social Europe can do for you. European Communities (2008) Longitudinal Studies Centre: Once a NEET always a NEET? Longitudinal Studies Centre, Scotland (2008), http://www.lscs.ac.uk/sls/projects/2008_007.htm (accessed January 13, 2009) 
National Audit Office: Connexions Service Advice and Guidance. The Stationery Office, London (2004)

Passey, D., Williams, S., Rogers, C.: Assessing the potential of e-learning to support reengagement amongst young people with Not in education, employment or training (NEET) status: An independent research and evaluation study. Background report: Becta, Coventry (2008), http: / / partners.becta.org.uk/upload-dir/downloads / page_documents/research/elearning_reengagement_neet_ background.pdf (accessed April 13, 2008)

Raffe, D.: Young People Not in Education, Employment or Training. Centre for Educational sociology, University of Edinburgh (2003),

http://www. ces.ed.ac.uk/PDF。20Files/Brief029.pdf

(accessed July 11, 2007)

Sachdev, D., Harries, B., Roberts, T.: Regional and sub-regional variation in NEETs - reasons, remedies and impact. Final report. LSDA, London (2006)

Shoesmith, P.: The use of data and associated issues. Presentation at the Learning and Technology World Forum, London (January 12, 2009) 